\title{
Computed tomography of brain in eclampsia and its clinical correlation
}

\author{
Sangita Mahela, Hemkanta Dev Sarma, Trailokya Mech, Bharat Talukdar
}

\author{
Corresponding author: Dr. Bharat Talukdar, Assistant Professor, Department of Obstetrics and \\ Gynaecology, Fakhruddin Ali Ahmed Medical College, Barpeta, Assam, India; \\ Email : talukdarbharat@gmail.com
}

Distributed under Attribution-Non Commercial - Share Alike 4.0 International (CC BY-NC-SA 4.0)

\begin{abstract}
Objective: The aim of the study was to identify intracerebral lesion in computed tomography (CT) imaging of eclampsia and correlate them with clinical manifestations. Methodology: This prospective study was carried out in the high dependency unit (HDU) of department of obstetrics and gynaecology in a tertiary care hospital for a period of one year. Total 45 women were included and were divided into two groups: a) study group: abnormal CT findings, b) control group: normal CT findings. Comparison was done using chi-square test. Results: Out of 45 numbers of cases $33.33 \%$ ( 15 women) had changes in brain CT scan. We observed 10 cases of cerebral oedema, 3 cases of cerebral infarction, and 2 cases of cerebral hemorrhage. The blurring of vision, multiple numbers of seizures, altered sensorium and unconsciousness showed statistically significant difference between the study and control group. The most common lobe involvement was occipital lobe (14 cases). There were five numbers of maternal mortality among 45 cases. All the 2 cases who had intracerebral haemorrhage died. Conclusion: The dominant intracerebral finding of eclamptic patient was cerebral oedema. Blurring of vision, multiple number of seizures, altered sensorium and unconsciousness were warning clinical presentations for possible brain lesions in CT scan.
\end{abstract}

Keywords: Eclampsia, cerebral edema, CT scan.

The prevalence of eclampsia in developing countries like India is $0.5 \%$ that was observed in a randomised controlled trial undertaken between 1 April 2016 and 30 November $2017^{1}$. The evaluation for eclampsia is centered around the diagnosis of preeclampsia. The definition for preeclampsia initially included proteinuria as a diagnostic requirement, but this is no longer the case as some patients had the advanced disease before proteinuria detection. Preeclampsia is defined as a new-onset of hypertension with systolic blood pressure greater than or equal to $140 \mathrm{mmHg}$ and/or diastolic blood pressure greater than or equal to $90 \mathrm{mmHg}$ after 20 weeks of gestation with proteinuria and/or end-organ dysfunction (renal dysfunction, liver dysfunction, central nervous system disturbances, pulmonary edema, and thrombocytopenia) ${ }^{2,3}$. Eclampsia is defined as the new onset of generalized tonicclonic seizures in a woman with preeclampsia. Eclamptic seizures can occur antepartum, 20 weeks after gestation, intrapartum, and postpartum.

Women under 20 years of age, and primigravida are dominant risk factors ${ }^{4}$. Eclampsia is related to adverse outcomes including cerebral hemorrhage, stroke, seizures, cardiopulmonary compromise, renal failure, liver hematoma or rupture, placental abruption, preterm delivery and death. Cerebral complications are the major cause of death. The

Received: $28^{\text {th }}$ March 2021, Peer review completed: $22^{\text {th }}$ May 2021, Accepted: $5^{\text {th }}$ June 2021.

Mahela S, Sarma HD, Mech T, Talukdar B. Computed tomography of brain in eclampsia and its clinical correlation. The New Indian Journal of OBGYN. 2021; 8(1): 14-8. 
The New Indian Journal of OBGYN. 2021 (July-December);8(1)

spectrum of brain involvement is wide, and these lesions include intracerebral hemorrhage, cerebral ischemia, and cerebral edema ${ }^{5}$. The intracerebral involvement can be better identified by using computed tomography (CT) imaging. The objectives of the present study were to correlate the computed tomography imaging findings and clinical presentation in eclampsia patients.

\section{Materials and methods}

This prospective study was carried out in the high dependency unit (HDU) of department of obstetrics \& gynaecology in Fakhruddin Ali Ahmed Medical College during the period of January 2019 to December 2019 after getting the permission from institutional ethical committee. All cases of eclampsia admitted in HDU were included in the study except the known cases of seizure disorder, chronic hypertension, trauma, space occupying lesion of brain, seizures due to metabolic disturbances, intracerebral infections.

$$
\text { Detailed history including socio- }
$$
demographic history, history of convulsion, obstetrical history and past medical history was elicited. General and systemic examination including neurological examination and investigations such as complete haemogram, urine albumin (by dipstick), liver function test, renal function test, absolute platelet count were done.

The selected women were sent to the radiology department for CT scanning of brain within 72 hours of admission. In antepartum cases CT scan were done after termination of pregnancy. If spontaneous delivery had not occurred then delivery of fetus was done either by induction of labour or caesarian section. All patients were treated with Pritchard regiment of $\mathrm{MgSo}_{4}$ and proper monitoring such as urine output, knee jerk and respiratory rate was done.

Total 45 women were included according to inclusion criteria and were divided into two groups: a) study group: abnormal CT findings, b) control group: normal CT findings.

The data were expressed as rates, ratios and proportions and comparison was done using chi-square test. A probability value ( $\mathrm{p}$ value) of less than 0.05 was considered as statistically significant.

\section{Results}

Total 45 numbers of women were included in the study. These women were divided in two groups. Study group $(\mathrm{n}=15)$ consisted of eclamptic women having abnormal CT scan findings and control group $(n=30)$ with no findings in CT scan. Dominant age in both groups was below 20 years. The mean age of the study population was $20.67 \pm 3.81$ years. No statistical significant difference observed in age wise distribution (p: 0.789) (table 1). In this study, 91.11\% $(n=41)$ women belonged to rural area. However geographical distribution in both groups was statistically non significant (p: 0.548$)$. Most of the women were primigravida (75.55\%).

\begin{tabular}{lllll}
\multicolumn{6}{l}{ Table 1: Table showing age, geographical distribution, parity and time of presentation } \\
\hline Parameters & \multicolumn{5}{c}{$\begin{array}{l}\text { Study Group } \\
\text { CT findings present } \\
\text { N=15 }\end{array}$} & $\begin{array}{l}\text { Control Group } \\
\text { CT findings absent } \\
\mathbf{N = 3 0}\end{array}$ & P value \\
\hline Age in years & $<20$ & 11 & 19 & 0.789 \\
& $20-25$ & 3 & 6 & \\
& $26-30$ & 1 & 4 & 0.548 \\
& $>30$ & - & 1 & 0.746 \\
\hline Geographic & Rural & 13 & 28 & \\
distribution & Urban & 2 & 2 & 0.586 \\
\hline Parity & 0 & 11 & 23 & \\
& 1 & 2 & 5 & \\
\hline Time of & 2 & 2 & 2 & \\
presentation & Antepartum & 8 & 10 & \\
\hline
\end{tabular}

Among all women 62.22\% (28 women) presented as antepartum and $37.78 \%$ ( 17 women) presented as postpartum eclampsia (table 1). The distribution of parity and time of presentation was also statistically non significant.

In this study, the comparison of clinical presentations was done. Vomiting, frothing, headache and urinary incontinence did not show statistically significant difference between the study and control group. There were statistically significant difference in clinical presentation like blurring of vision, number of convulsion, altered sensorium and

Table 2: Clinical presentation

\begin{tabular}{llll}
\hline Parameters & $\begin{array}{l}\text { Study Group } \\
\text { Ct findings present } \\
\text { N=15 }\end{array}$ & $\begin{array}{l}\text { Control Group } \\
\text { CT findings absent } \\
\text { N=30 }\end{array}$ & P value \\
\hline Vomiting & 2 & 10 & \\
Frothing & 4 & 11 & 0.153 \\
Headache & 5 & 15 & 0.502 \\
Blurring of vision & 7 & 4 & 0.228 \\
Urinary incontinence & 1 & 2 & 0.014 \\
2 convulsions & 6 & 28 & 1.000 \\
3 or more convulsions & 9 & 2 & 0.000 \\
Altered sensorium & 5 & 1 & 0.000 \\
Unconscious & 8 & 1 & 0.005 \\
\hline
\end{tabular}
unconsciousness between the two groups (table 2).

Out of 45 numbers of eclamptic women $33.33 \%$ (15 women) had changes in brain on CT scan. Among the types of lesion the dominant finding was cerebral oedema (10 cases) (figure 1) followed by cerebral infarction (3 cases) and cerebral haemorrhage ( 2 cases) (table 3 ). 
The New Indian Journal of OBGYN. 2021 (July-December);8(1)

In this study, the most common lobe involvement was occipital lobe (14 cases) followed by parietal ( 8 cases), temporal ( 7 cases), frontal ( 3 cases) (table 4 ). Most of the lesions showed bilateral distribution with involvement of different lobes.

Table 3: Types of cerebral lesion

\begin{tabular}{ll}
\hline Types & Number \\
\hline Cerebral oedema & 10 \\
Cerebral infarction & 3 \\
Cerebral haemorrhage & 2 \\
Normal & 30 \\
\hline
\end{tabular}

On CT scan the dominant presentation was PRES (posterior reversible encephalopathy syndrome) (35.5\%). Clinically other maternal complications such as pulmonary oedema, status eclampticus, PPH (postpartum haemorrhage), ARF (acute renal failure) and neurological deficit were

\begin{tabular}{ll} 
Table 4: Involvement of area of brain & \\
\hline Anatomical site & Number \\
\hline Occipital lobe & 14 \\
Parietal lobe & 8 \\
Temporal lobe & 7 \\
Frontal lobe & 3 \\
\hline
\end{tabular}

observed in 2(4.44\%), 2(4.44\%), 1(2.22\%), 1(2.22\%) and $1(2.22 \%)$ cases respectively (table 5). Among 45 number of cases, 5 maternal deaths occurred which were due to pulmonary oedema (1 case), status eclampticus (1 case), cerebral haemorrhage ( 2 cases) and PPH (1 case). Four of the maternal death were belonged to study group and one belonged to control group. The cause of maternal death in control group was severe PPH.

Table 5: Maternal outcomes

\begin{tabular}{ll}
\hline Category & Number (\%) \\
\hline Pulmonary oedema & $2(4.44 \%)$ \\
PRES & $16(35.56 \%)$ \\
Status eclampticus & $2(4.44 \%)$ \\
PPH & $1(2.22 \%)$ \\
ARF & $1(2.22 \%)$ \\
Neurological deficit & $1(2.22 \%)$ \\
\hline PRES - Posterior reversible encephalopathy syndrome, PPH - \\
Postpartum haemorrhage, ARF - Acute renal failure \\
\hline
\end{tabular}

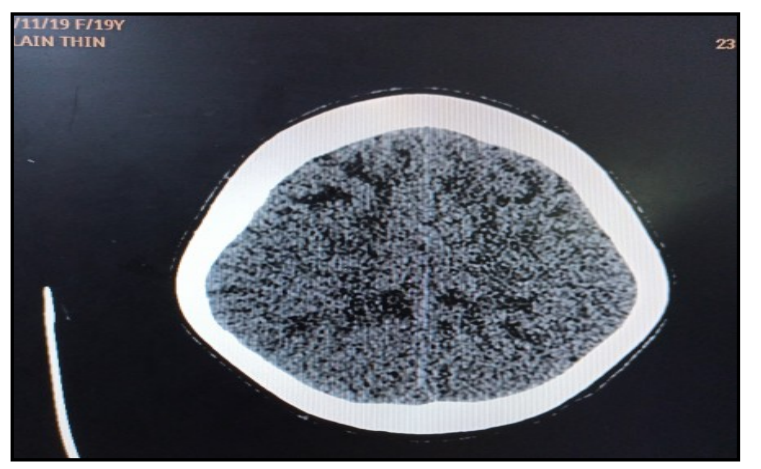

Figure 1: Ill defined hypodensities involving bilateral frontal and parietal lobes involving white matter - Cerebral oedema

\section{Discussion}

The mean age of eclamptic mother in this study was $20.67 \pm 3.81$ years. The dominant number of primigravida $(75.55 \%)$ was in category of below 20 years. Existing literature suggests that teenage pregnant women are at greater risk of eclampsia ${ }^{6}$. These results were also similar to case series study of 30 eclamptic patient conducted by Jindal MA et al. They reported that the maximum number of eclamptic patient belonged to category of 20 to 25 years $(60 \%)^{7}$. A study by Dahiya $\mathrm{K}$ et al reported that the mean age of eclamptic women $22.61 \pm 2.72$ years which was comparable with the present study ${ }^{8}$. Another study by Robert A et al showed that incidence of pregnancy associated hypertension and eclampsia decreased with increased age during adolescence. They also observed that the incidence of eclampsia was significantly lower in gravida two (G2) than gravida one (G1) ${ }^{9}$.

This observation was comparable to our study. In this study, the distribution of antepartum and postpartum eclampsia was $62.22 \% \quad(n=28)$ and $37.78 \% \quad(n=17)$ respectively. These findings were consistent with the study by Gurjar B et al ${ }^{8}$ who reported that most of their cases as antepartum eclampsia ${ }^{10}$. Similarly more number of antenatal eclampsia was observed in the study by Chakravarty A et $\mathrm{al}^{11}$ and Majoko $\mathrm{F}$ et al ${ }^{12}$.

In this study, the comparison of clinical presentations such as blurring of vision, two numbers of convulsions, $\geq 3$ numbers of convulsions, altered sensorium and unconsciousness, showed statistically significant difference between the study and control group $(\mathrm{p}=0.014, \mathrm{p}=0.000$, $\mathrm{p}=0.000, \mathrm{p}=0.005, \mathrm{p}=0.000$ respectively). The other clinical manifestations such as vomiting, frothing, headache and urinary incontinence did not show statistically significant difference. A study by Dahiya $\mathrm{K}$ et al reported significant difference between study group and control group regarding clinical manifestation such as unconsciousness, altered sensorium, headache, blurring of vision and seizures which was comparable with the present study ${ }^{2}$. Another Bangladeshi study showed similar statistically significant difference between the two groups regarding headache and visual disturbance ${ }^{13}$. Chang WN et al in a Taiwanese study also found comparable CT scan findings in eclamptic patients with headache and blurring of vision ${ }^{14}$.

We observed 10 cases of cerebral oedema, 3 cases of cerebral infraction, and 2 cases of cerebral haemorrhage. The CT scan was normal in 30 eclamptic cases. Cerebral oedema was the predominant finding in our study. Similar 
The New Indian Journal of OBGYN. 2021 (July-December);8(1)

observation was found in a French study, which observed 14 patients of cerebral oedema in 19 eclamptic women ${ }^{15}$. However, our study findings were contrast with some other study. A study in Cote d'Ivoire ${ }^{16}$, had been found a prevalence of almost equal number of ischemic and oedematous lesions whereas an Indian study, observed a prevalence of ischemic lesion ${ }^{17}$.

In our study, the locations of brain involvement were variously associated (parieto-occipital, parietal-occipitofrontal, occipital, and temporal). The most common lobe involvement was occipital lobe (14 cases) followed by parietal ( 8 cases), temporal ( 7 cases), frontal (3 cases). Similarly in a study of 76 eclamptic women by McKinney $\mathrm{AM}$ et al, reported that the incidence of site of involvement was parieto-occipital $98.7 \%$ and temporal $68.4 \%{ }^{18}$. In another study, Bartynski WS et al, described oedema in parietal or occipital regions $98 \%$ which was comparable with the present study ${ }^{19}$. However, in a study by Gurjar B et al reported that the most common lobe involved was parietal followed by occipital ${ }^{10}$.

In our study, the dominant presentation was posterior reversible encephalopathy syndrome (PRES) (35.5\%). A study by Lakhdar $\mathrm{R}$ et al reported $61.4 \%$ of cases of posterior reversible encephalopathy PRES in eclamptic patient ${ }^{20}$. Complications like pulmonary oedema, status eclampticus, $\mathrm{PPH}, \mathrm{ARF}$ and neurological deficit were observed in 2(4.44\%), 2(4.44\%), 1(2.22\%), 1(2.22\%) and $1(2.22 \%)$ cases respectively. Among 45 number cases, 5 maternal deaths occurred which were due to pulmonary oedema ( 1 case), status eclampticus (1 case), cerebral haemorrhage (2 cases) and PPH (1 case). Four of the maternal death belonged to study group and one belonged to control group. The cause of maternal death in control group was severe PPH. Patients with cerebral haemorrhage had poor prognosis in our study. Indeed, 2 patients who had presented with intracerebral haemorrhage died. The literature reported that intracerebral haemorrhage during eclampsia has a poor prognosis compared to ischemic stroke ${ }^{21}$.

\section{Conclusion}

Cerebral oedema was the predominant finding in our study. The most common lobe involvement was occipital lobe. Blurring of vision, multiple number of seizures, altered sensorium and unconsciousness were warning clinical presentations for possible brain lesions in CT scan.

Conflict of interest: None. Disclaimer: Nil.

\section{References}

1. Vousden N, Lawley E, Seed PT, Gidiri MF, Goudar S, Sandall J, Chappell LC, et al. Incidence of eclampsia and related complications across 10 low- and middleresource geographical regions: Secondary analysis of a cluster randomised controlled trial. PLOS Medicine. March 29, 2019. doi.org/10.1371/journal.pmed.1002775

2. Wilkerson RG, Ogunbodede AC. Hypertensive Disorders of Pregnancy. Emerg Med Clin North Am. 2019 May;37(2):301-6.

3. Sutton ALM, Harper LM, Tita ATN. Hypertensive Disorders in Pregnancy. Obstet Gynecol Clin North Am. 2018 Jun;45(2):333-47.

4. Abalos E, Cuesta C, Carroli G, Qureshi Z, Widmer M, Vogel JP, et al. Pre-eclampsia, eclampsia and adverse maternal and perinatal outcomes: a secondary analysis of the World Health Organization Multicountry Survey on Maternal and Newborn Health. BJOG. 2014;121(Suppl 1):14-24.

5. Harandou M, Madani N, Labibe S, Messouak O, Boujraf $\mathrm{S}$, Benkirane S. Neuroimaging findings in eclamptic patients still symptomatic after 24 hours: A descriptive study about 19 cases. Ann Fr Anesth Reanim. 2006; 25: 577-83.

6. Ganchimeg T, Ota E, Morisaki N, Laopaiboon M, Lumbiganon P, Zhang J, et al. Pregnancy and childbirth outcomes among adolescent mothers: a World Health Organization multicountry study. BJOG. 2014;121(Suppl 1):40-8.

7. Jindal MA, Gaikwad HS, Hasija BD, Vani K. Comparison of neuroimaging by $\mathrm{CT}$ and MRI and correlation with neurological presentation in eclampsia. International Journal of Reproduction, Contraception, Obstetrics and Gynecology. 2013; 2: 83-7.

8. Dahiya K, Rohilla S, Agarwal K, Rathod M, Dahiya. MRI Brain Lesions in Eclampsia: A Series of 50 Cases Admitted to HDU of a Tertiary Care Hospital. J Family Reprod Health. 2018 Mar; 12(1): 51-6.

9. Kellyanne R, Mark FG, Modilevsky ST. Effect of age, parity, and race on the incidence of pregnancy associated hypertension and eclampsia in the United States. Pregnancy Hypertension: An International Journal of Women's Cardiovascular Health. 2014; 4(1): 46-53.

10. Gurjar B, Rawat RP. CT scan findings in patients of eclampsia. Int J Reprod Contracept Obstet Gynecol. 2017 Aug; 6(8): 3405-8 
11. Chakravarty A, Chakrabarti SD. The neurology of eclampsia: some observations. Neurol India. 2002; 50:128-35.

12. Majoko F, Mujaji C. Maternal outcome in eclampsia at Harare Maternity Hospital. Cent Afr J Med. 2001; 47:123-8.

13. Begum F, Nahar K, Ahmed MU, Ferdousi RA, Akter FA, Rahman MM. Study on Neurological Manifestations of Eclampsia \& Findings of CT scan of Brain. Mymensingh Med J. 2015; 24: 691-6.

14. Chang WN, Lui CC, Chang JM. CT and MRI findings of eclampsia and their correlation with neurologic symptoms. Zhonghua Yi Xue Za Zhi (Taipei). 1996; 57: 191-7.

15. Harandou M, Madani N, Labibe S, Messouak O, Boujraf $\mathrm{S}$, Benkirane $\mathrm{S}$, et al. Neuroimaging findings in eclamptic patients still symptomatic after 24 hours: a descriptive study about 19 cases]. Ann Fr Anesth Reanim. 2006 Jun; 25(6):577-83.

16. Brouh Y, Jean KK, Ouattara A, Tétchi Y, Pete Y, Koffi N, et al. Brain lesions in eclampsia: A series of 39 cases admitted in an Intensive Care Unit. Indian J Crit Care Med. 2016 Mar; 20(3): 178-81

17. Ugran SM, Dominath KV. Correlation between neuroimaging (CT scan) and neurological presentation in antepartum and postpartum eclampsia.Int J Reprod C ontracept Obstet Gynecol. 2016 Feb;5(2):419-24.
18. McKinney AM, Short J, Truwit CL, McKinney ZJ, Kozak OS, Santa Guz KS, et al. Posterior reversible encephalopathy syndrome incidence of atypical region of involvement and imaging findings. Am J Roentgenol. 2007;189: 904-12.

19. Bartynski WS, Boardman JF. Distinct imaging pattern and lesion distribution in posterior reversible encephalopathy syndrome. Am J Neuroradiol. 2007; 28: $1320-7$.

20. Lakhdar R1, Baffoun N, Hammami N, Nagi S, Baccar K, Drissi S, Kaddour C. Neuroradiological pattern of peripartum cerebro vascular disease medicating transfer to determine care unit. Tunis Med. 2012; 90(3): 223-32

21. Jaigobin C, Silver FL. Stroke and pregnancy. Stroke. 2000; 31: 2948-51.

\footnotetext{
Sangita Mahela ${ }^{1}$, Hemkanta Dev Sarma ${ }^{2}$, Trailokya Mech $^{3}$, Bharat Talukdar ${ }^{4}$

${ }^{1}$ Assistant Professor, Department of Radiology, Fakhruddin Ali Ahmed Medical College, Barpeta, Assam, India; ${ }^{2}$ Assistant Professor, Department of Obstetrics and Gynaecology, Fakhruddin Ali Ahmed Medical College, Barpeta,Assam; ${ }^{3}$ Consultant Radiologist, Alcare Diagnostic Centre, Bhangagarh, Guwahati, Assam; ${ }^{4}$ Assistant Professor, Department of Obstetrics and Gynaecology, Fakhruddin Ali Ahmed Medical College, Barpeta, Assam, India.
} 